\title{
Ecossistemas de Aprendizagem e o Futuro da Educação
}

\author{
Pedro David Netto Silveira ${ }^{1}$, Davidson Cury ${ }^{1}$, Orivaldo Tavares ${ }^{1}$, Crediné Silva de \\ Menezes $^{2}$, Rosane Aragón ${ }^{3}$, Alberto Nogueira de Castro Junior ${ }^{4}$, Thais Helena \\ Chaves de Castro ${ }^{4}$
}

\author{
${ }^{1}$ Programa de Pós-graduação em Informática \\ Universidade Federal do Espírito Santo (UFES) - Vitória, ES - Brasil \\ ${ }^{2}$ Programa de Pós-graduação em Informática na Educação \\ Universidade Federal do Rio Grande do Sul (UFRGS) - Porto Alegre, RS - Brasil \\ ${ }^{3}$ Programa de Pós-graduação em Educação \\ Universidade Federal do Rio Grande do Sul (UFRGS) - Porto Alegre, RS - Brasil \\ ${ }^{4}$ Instituto de Computação \\ Universidade Federal do Amazonas (UFAM) - Manaus, AM - Brasil \\ pedro.dns@gmail.com, dedecury@gmail.com, tavares@inf.ufes.br, credine@gmail.com, \\ rosane.aragon@ufrgs.br, alberto@icomp.ufam.edu.br, thais.helena@gmail.com
}

\begin{abstract}
In this paper we discuss what is expected from education for the next 10 years from a learning ecosystem viewpoint. We believe that in the future, education will be guided by personalization and informality of learning and the challenge is in to make it happen with quality and in a systematic way.
\end{abstract}

Resumo. Neste artigo discutimos o que se espera da educação nos próximos 10 anos sob o ponto de vista do fomento aos ecossistemas de aprendizagem. Acreditamos que no futuro, a educação será pautada pela personalização e informalidade da aprendizagem e o desafio está em fazer isso acontecer de forma sistêmica e com qualidade.

\section{Introdução}

Segundo Willis (2013), a personalização, a colaboração e a aprendizagem informal estarão no centro da aprendizagem no futuro, que será potencializada pela ubiquidade das tecnologias de informação e comunicação, expectativa concordante com um importante relatório prospectivo da Comissão Europeia que discute a aprendizagem em 2030 [Redecker et al, 2011]. Segundo Jackson (2013), o conceito de ecossistema de aprendizagem (EA) compreende a relação de interdependência e coexistência encontrada nas interações entre indivíduos e com dos indivíduos com o ambiente onde estejam inseridos. Nosso desafio é consonante com esse contexto: Personalizar e favorecer a aprendizagem colaborativa e informal, considerando os EA já existentes e os que ainda surgirão.

O modo como movimentamos nosso dinheiro, como nos locomovemos de um ponto a outro, como consumimos produtos e serviços, já são fortemente influenciados por tecnologias "inteligentes". Ao considerar o advento da cultura digital, povoada por internet das coisas, tecnologias ubíquas, wereables, etc, os EA ganham um suporte inestimável para a coleta de dados e o uso dos mesmos para favorecer a reflexão sobre as trajetórias vivenciadas, bem como para estabelecer novas interações motivadas por objetivos comuns de aprendizagem, apoiadas por ferramentas cognitivas.

Há alguns anos, os cientistas cognitivos concentram-se na discussão de dois 
VIII Congresso Brasileiro de Informática na Educação (CBIE 2019)

Anais do VIII Workshop de Desafios da Computação aplicada à Educação (DesafIE 2019)

tipos de conhecimento, os quais podem ser representados resumidamente em "conhecimento sobre" e "conhecimento de" algo. O segundo é ativado quando uma necessidade de realização de algo é encontrada em ação. Enquanto o primeiro é equivalente ao conhecimento declarativo e é acionado quando uma explicação simples é necessária. O "conhecimento sobre" domina a prática educacional tradicional. É o material de livros didáticos, diretrizes curriculares, testes de matérias e projetos típicos da escola e documentos de pesquisa. "O conhecimento de", por outro lado, sofre negligência maciça e isso é um problema, pois na construção do conhecimento, os alunos trabalham com situações que resultam em profundo conhecimento estrutural de [Scardamalia and Bereiter 2006].

Entendemos que existem muitas dificuldades inerentes ao favorecimento da aprendizagem colaborativa e informal. A escola tradicional, não está preparada para esse advento [Collins and Halverson 2018] e o grande desafio está em quebrar esse paradigma, fortalecendo em nossos estudante a prática de desenvolvimento do "conhecimento de", buscando uma aprendizagem sem fronteiras.

\section{Aprendizagem sem fronteiras}

Com o aporte dos ecossistemas de aprendizagem na cultura digital (EACD), as escolas se tornarão espaços onde os todos decidem juntos quais caminhos prosseguir: projetos colaborativos, atividades de aprendizagem especializadas, lugares para ver e coisas para fazer (Lemke, 2013). Mas não apenas isso, com os EACD seremos capazes de aprender em qualquer lugar e a qualquer hora, não apenas na escola, não apenas estudando, mas em qualquer atividade que estejamos desenvolvendo. Aprenderemos sem fronteiras.

De acordo com Silveira, Cury and Menezes (2019) existem cinco principais limitações da escola tradicional que chamamos de fronteiras da educação e são elas: (i) física-temporal: só aprender em um determinado local em um horário estabelecido, (ii) virtual: reproduzir no mundo da $\mathrm{EaD}$, limitações físicas da escola (iii) interdisciplinaridade: descontextualização da aprendizagem provocada pela separação em disciplinas (iv) hierárquica: um indivíduo ensina e outro aprende e (v) padronização: aprendemos somente se exploramos conteúdos.

Para superar o desafio dessas limitações é necessário a concepção de aplicações tecnológicas que objetivem alicerçar a educação auxiliando estudantes como por exemplo: evitar tarefas desnecessárias; capturar aquilo que seus sentidos podem requerer e ele ainda nem saiba o quê; perceber no que eles devem focar, em contextos onde muitas coisas acontecem ao mesmo tempo; buscar, registrar e recuperar mais informação, daquilo que está sendo aprendido; etc.

Além das concepções tecnológicas, para suplantar as fronteiras e fortalecer o desenvolvimento estrutural do "conhecimento de", é essencial atualizar as práticas pedagógicas habituais moldadas pelo instrucionismo clássico. Para isso, um grupo de pesquisadores da UFES, UFRGS e UFAM (que pode ser acrescido com mais entusiastas da educação) têm trabalhado colaborativamente considerando diversos tópicos para o processo de remodelagem das práticas pedagógicas atuais, tornando o estudante um protagonista na construção do seu próprio conhecimento. Dentre esses tópicos, destacam-se o pensamento computacional (PC) e as arquiteturas pedagógicas (AP) aderidos aos ecossistemas de aprendizagem (EA).

A construção do conhecimento por meio de arquiteturas pedagógicas pode 
acontecer em diversos ambientes, e não se limitam a características de uma sala de aula convencional. Elas foram concebidas de forma a acolher pedagogias abertas, maleáveis e flexíveis para promover novos modos de conhecer e fomentar o pensamento em rede por meio de mediação pedagógica [Menezes and Nevado 2018].

\section{Considerações finais}

Um cuidado muito especial deve ser observado. Nós devemos usar a tecnologia, e não o contrário. Quando permitimos que nossos smartphones nos digam o que fazer, como por exemplo que rota utilizar no trânsito, ou que produtos comprar ou ainda que atividades são mais adequadas a nosso perfil, é importante estabelecer o limite sobre até onde precisamos de ajuda para tomar nossas decisões e manter nossa naturalidade de ser humano, mesmo que isso acarrete em erros esporádicos. Lembremo-nos que os erros também são importantes para a equilibração da aprendizagem.

Sabemos que novas tecnologias podem ajudar a simular e falar sobre as atividades típicas da comunidade muito melhor do que o professor médio na sala de aula média. No entanto, as tecnologias ou os ECs, não poderão substituir a participação direta ou a orientação ponderada da reflexão e análise críticas dos alunos, nem o incentivo emocional da realização e criatividade que os professores proporcionam. Para estes fins, os professores profissionais serão sempre necessários, especialmente para os estudantes mais jovens (Lemke, 2013).

\section{Referências}

Collins, A. and Halverson, R. (2018). Rethinking education in the age of technology: The digital revolution and schooling in America. Teachers College Press.

Redecker, C., Leis, M., Leendertse, M., Punie, Y., Gijsbers, G., Kirschner, P. Stoyanov, S. and Hoogveld, B. (2011) "The Future of Learning: Preparing for Change". European Commission Joint Research Centre Institute for Prospective Technological Studies EUR 24960 EN Luxembourg: Publications Office of the European Union.

Willis, Jenny (Ed). (2013) “Learning Ecologies”. L.W. Magazine, n. 7.

Lemke, J. (2013) "Becoming a village: An ecological perspective”. L.W. Magazine, n. 7.

Menezes, C. S. and de Nevado, R. A. (2018). Arquiteturas pedagógicas para aprendizagem ativa. In:10th International Symposium on Project Approaches in Engineerin gEducation (PAEE).

Scardamalia, M. and Bereiter, C. (2006). Knowledge building: Theory, pedagogy, andtechnology. In Sawyer, K., editor,Cambridge Handbook of the Learning Sciences,pages 97-118. Cambridge University Press, New York.

Silveira, P. N., Cury, D., de Menezes, C. (2019) "Superando fronteiras da educação com ecossistemas de aprendizagem". In: Brazilian Symposium on Computers in Education (Simpósio Brasileiro de Informática na Educação-SBIE). 